\title{
Nutrient level \& its effect on cognition among ASD children in Bangladesh: a cross-sectional study
}

\begin{abstract}
Background: Autism is a disorder of neural development characterized by impaired social interaction and communication and also by restricted as well as repetitive behavior.

Method: A cross-sectional study. A total of 384 children (age group 1-12 years) with autism were enrolled in this study. The parents were asked to complete the questionnaire regarding the socio-demographic and eating behavior of their children. They were also asked to provide a 24-hour Re-call method by average of three days food diary. IQ assessment was done with Bayley Scales of infant development (BSID), Independent Behavior Assessment Scale (IBAS), Wechsler Intelligence Scale for Children-Revised (WISC-R). Data analysis was done by SPSS version 20.

Result: Energy intake was lower than the RDA in all age group of the autistic children. Mean intake of protein \& calcium were higher than the RDA in all age group of the autistic children but in fat intake it was lower in only 10-12y age group. In case of mean intake of iron it was higher than the RDA in all the age group except 7-9 years \& 10-12years age group. VitA, thiamine, VitC intake were lower than the RDA. In case of riboflavin \& niacin in two age group 1-3 years \& 4-6years they were higher than the RDA but in age group 7-9y \& 10-12y it was lower than the RDA. Deficient intake of protein, thiamine, niacin \& zinc, which was highly significant with low IQ level of the autistic children (P value was .00).
\end{abstract}

Conclusion: Children with autism exhibited several abnormalities in terms of eating behavior.

Keywords: autism spectrum disorder, IQ, nutrients

\author{
Volume 7 Issue 6 - 2018
}

\author{
Jannatara Shefa,' Khaleda Islam, ${ }^{2}$ Mohammad \\ Ferdous Ur Rahaman ${ }^{3}$ \\ 'Bangabandhu Sheikh Mujib Medical University (BSMMU), \\ Bangladesh \\ 2University of Dhaka, Bangladesh \\ ${ }^{3}$ Department of Internal Medicine, Bangabandhu Sheikh Mujib \\ Medical University (BSMMU), Bangladesh
}

\begin{abstract}
Correspondence: Jannatara Shefa, Research Medical Officer, Institute of Pediatric Neurodisorder \& Autism (IPNA), Bangabandhu Sheikh Mujib Medical University (BSMMU), Dhaka, Bangladesh,Tel+880 I7I5254283, Email shefafnan@yahoo.com
\end{abstract}

\author{
Received: September 25, 2018 | Published: November I6, \\ 2018
}

\section{Introduction}

A neural developmental disorder characterized by impaired social interaction and communication, along with restricted and repetitive behavior is Autism. Autism not only information processing in the brain but also altering the nerve cells and their synapses connect and organize. However how does this occur is not well understood. ${ }^{1}$ The first appearance of autism starts during infancy or childhood, and generally follows a steady course without remission. ${ }^{2}$ Most of the symptoms gradually begin after the age of six months, and on established by age two or three years ${ }^{3}$ and after that it would be continue through adulthood, but most of the time in more muted form. ${ }^{4}$ It could not be identified by a single symptom, but with a characteristic triad of symptoms it could be easily identified. Sometimes atypical eating, are also common although not essential for the diagnosis. ${ }^{5}$ Early childhood is a period when children experience new foods, tastes, and textures. Parents of toddlers and young children often describe their children as "picky eaters", refusing to try or eat a variety of foods. Although picky eating is not uncommon among young children who are typically developing, pickiness in children with autism spectrum disorders (ASDs) may be even more restrictive and may extend beyond the early childhood period. ${ }^{6-8}$ In a human body brain is the largest organ which need food \& drink for development like any other organ. But the linkage between this diet and brain cells yet unrecognized. In so many research it would be clear that for dietary intake brainwork has been depend which ultimately influence our live. These procedures may be started from early infancy of life. For example, $70 \%$ of the energy absorbed by a fetus during pregnancy is directed towards brain development. So every stage of life the correlation of diet $\&$ brain has been observed. Mental health and well-being varies on significant diet, but there appears to be no point at which diet has no effect. Although there are different researches looking into important aspects of autistic patients, these have not sufficiently covered the issue of nutritional status and the intelligence capacity. From the existing literature indication is found that there is strong connection between autism, nutritional status and the IQ level.

\section{Methodology}

This study focuses nutritional status and IQ level of the autistic children at a single point in a specified time. Considering time period and resource availability, cross-sectional analytical (to show association, correlation, regression among different variables study design was most feasible for this study). Since the number of the population was precisely unknown in Bangladesh but presumably which will be few thousands, the minimum sample size was estimated.

The sample size was use: $n=Z^{2} p q / d^{2}$

Where, $\mathrm{n}=$ required sample size, $\mathrm{Z}=$ standardized normal variable, $\mathrm{p}=$ proportion of autistic children (unknown), $\mathrm{q}=1-\mathrm{p}, \mathrm{d}=$ degree of accuracy desired which is set at 5\% level. So sample size of 384 was reasonable one. In this respect margin of error was considered $5 \%$ and confidence interval $95 \%$. In addition it was ensured that the age of the sample is 1 to 12 years. The study had been conducting among autistic children (age 1-12 years) who were diagnosed by Pediatric Neurologist \& Psychologist clinically at selected centers in Bangladesh where patients come from different parts of Bangladesh. 
Data were collected from outpatient department (OPD) of Institute of Pediatric Neurodisorder \& Autism (IPNA), BSMMU, OPD of The Centre for the Rehabilitation of the Paralyzed (CRP) in Dhaka, Savar \& also specialized centers like: Autism Welfare foundation, The Society for the Welfare of Autistic Children (SWAC), Autistic Children's Welfare Foundation, Bangladesh Jatio Protibondhi Unnoyon Foundation (JPUF), Dhaka. All those hospitals \& centers are working with children of autism spectrum disorder. In those centers autism screening, diagnosis, psychological test, management $\&$ treatment are given.

\section{Study questionnaire}

For demographic data collection part of the questionnaire was drafted by the researcher with the help of supervisor \& other experts of INFS, University of Dhaka. The Bangla translation of questionnaires also had been drafted at that time. The questionnaire used for the study contains 8 modules and a total of 35 questions. Anthropometric measurement module was prepared for measuring the height/length, weight of children of age 1 to 12 years. For measuring height/length local made wooden stadiometer was used, for taking weight digital weighing scale (Bathroom scale) was used. IQ assessment tools used by the psychologist were: Bayley Scales of infant development (BSID II), Independent Behavior Assessment Scale (IBAS), Stamford- Binet Intelligence Scale, Wechsler Intelligence Scale for Children-Revised (WISC-R)

\section{Study subject}

The children (age 1-12 years) who were diagnosed by Pediatric Neurologist and Psychologist clinically as a children of Autism Spectrum Disorder (age 1-12 years) at OPD of Pediatric Neurology Department was study subject. ASD children of different specialized centers were also taken as a study subject. It would be observed that most of the urban, educated parents were coming with their children by recognizing symptoms of autism. But now-a-days people in low socio-economic status also come to the service provider for diagnosis $\&$ management of the children with autism but they are poor in number.

\section{Study procedure}

After approval of the study protocol by Dhaka University syndicate and getting permission from respective department, the study was conducted. Children (age 1-12 years) who were referred or come individually in to the OPD of different hospitals diagnosed as ASD were included in the study. After taking written informed consent from the parents (or legal guardian, attendant), pre-tested questionnaires were fill-up, IQ level were collected from psychologist during data collection \& height-weight were also measured by the researcher own. The module on "24 Hours Recall Method" (which is universal) contains 5 items of questions where answer would be comprises of different food items. Keeping consistence with the general and specific objectives of the study and terms of reference, the draft questionnaires for nutritional assessment was designed based on the base questionnaires of INFS food data analysis software. The questionnaire was pre-tested on OPD of IPNA, BSMMU at first.

\section{Statistical analysis}

To analyze the data Statistical Package for Social Science (SPSS) version 21.0 was used. After entry, range and consistency were checked. Statistical analysis was done by using descriptive statistics. Continuous variables were presented as mean values \pm standard deviation (SD), and categorical variables were presented as percentages. For data appropriateness significance test ( $\mathrm{T}$ test, chi-square test, correlation test and coefficient of variation) was done. Food data were analyzed by software of INFS, University of Dhaka. After macro \& micro-nutrient analysis that were compared with demographic data. Data were presented by table and charts. IQ level was measured in different psychological test by registered psychologist, which were also compared with nutritional status \& food intake. Data were presented by table and charts. IQ level was measured in different psychological test by registered psychologist, which were also compared with food intake.

\section{Ethical consideration}

An ethical permission was taken from IRB of Dhaka University. The study was conducted maintaining all possible ethical considerations. Informed written consent was obtained before data collection. Informed consent was taken from all contain purposes, methods and benefits of the study. During interview, all sorts of privacy of the data providers were maintained. Confidentiality of data was ensured strictly. Data were preserved in computer and will be used only for the purpose of this research.

\section{Findings of the study}

After analysis it was found most of the children (37\%) were in the 37-71 months of age group, 26\% were $72-107$ months, $20 \%$ were in $108-120$ months \& $17 \%$ were in $<36$ months. It was observed in case of autism male children were more affected than female children. There were $82 \%$ male children and female children were $18 \%$.It was revealed that in Bangladesh most of the participants were Muslim, 90\% followed by Hindu $8 \%$ and Buddhist $\%$. Age (in years) distribution of the autistic child's parents $(n=384)$, mother's mean age were 25 years where SD 5.10 \& father's age were 33 years where SD 5.58, when the children with autism was born. Regarding the educational level of the mother of the autistic children, $24.7 \%$ completed postgraduation, $29.4 \%$ completed graduation, $41.7 \%$ completed secondary to higher-secondary level \& only $4.2 \%$ completed primary education level. Most of the parent (51\%) had family income 30000-59999 taka monthly, $27.2 \%$ had $<30,000$ taka \& $22 \%$ parents had monthly income 60,000 taka $\&$ above (Table 1). In Table 2 number of autistic children who underwent psychological test was 384 . Among them more than $63 \%$ autistic children had IQ level $<69$ (known as significantly delayed performance by standard method), 24\% had IQ level 70-85 (known as moderately delayed performance) \& nearly $12 \%$ of the children had IQ level 85-114 (known as mildly delayed performance). In case of psychological test $94 \%$ were done by BSID II (Bayley Scales of infant development), 3\% were done by WISC-R (Wechsler Intelligence Scale for Children-Revised) \& 3\% were done by IBAS (Independent Behavior Assessment Scale) (Table 2). In Table 3 mean per capita food intake in different age group was calculated. Age group 1-3y, $4-6 y, 7-9 y, 10-12 y$ had consumed cereal 189gm, 155gm, 168gm \& $179 \mathrm{gm}$ respectively. Age group 1-3y, 4-6y,7-9y,10-12y had consumed rice $132 \mathrm{gm}, 102 \mathrm{gm}, 120 \mathrm{gm} \& 131 \mathrm{gm}$ respectively. Age group 1-3y, $4-6 \mathrm{y}, 7-9 \mathrm{y}, 10-12 \mathrm{y}$ had consumed potatoes $5 \mathrm{gm}, 09 \mathrm{gm}, 12 \mathrm{gm} \& 13$ gm respectively. Age group 1-3y, 4-6y,7-9y,10-12y had consumed pulse \& nut $3 \mathrm{gm}, 7 \mathrm{gm}, 8 \mathrm{gm} \& 10 \mathrm{gm}$ respectively. Age group 1-3y, 4-6y, 7-9y had consumed vegetables $8 \mathrm{gm}, 18 \mathrm{gm}, 22 \mathrm{gm} \&$ age group $7-9 \mathrm{y}$ had $19 \mathrm{gm}$ consumption. Age group 1-3y, 4-6y,7-9y,10-12y had consumed fruits $20 \mathrm{gm}, 21 \mathrm{gm}, 22 \mathrm{gm} \& 18 \mathrm{gm}$ respectively. Age group 
$1-3 \mathrm{y}, 4-6 \mathrm{y}, 7-9 \mathrm{y}, 10-12 \mathrm{y}$ had consumed poultry $12 \mathrm{gm}, 25 \mathrm{gm}, 42 \mathrm{gm} \&$ $64 \mathrm{gm}$ respectively. Age group 1-3y, 4-6y,7-9y,10-12y had consumed fish $37 \mathrm{gm}, 58 \mathrm{gm}, 53 \mathrm{gm} \& 44 \mathrm{gm}$ respectively. Age group 1-3y, 4-6y,7$9 \mathrm{y}, 10-12 \mathrm{y}$ had consumed milk \& milk products $130 \mathrm{gm}, 133 \mathrm{gm}$, $75 \mathrm{gm} \& 40 \mathrm{gm}$ respectively. In Table:4 mean per capita consumption of different kind of nutrient were calculated. Age group 1-3y, 4-6y, $7-9 \mathrm{y}, 10-12 \mathrm{y}$ had consumed energy $852.8 \mathrm{kcal}, 804.8 \mathrm{kcal}, 845.6 \mathrm{kcal}$ $\& 871.3 \mathrm{kcal}$ respectively. Except 1-3 years age group, energy intake was lower than the RDA in all age group of the autistic children. Mean intake of protein \& calcium were higher than the RDA in all age group of the autistic children but in fat intake it was lower in only $10-12 y$

Table I Baseline characteristics of the study subjects $(n=384)$ age group. In case of mean intake of iron were higher than the RDA in all the age group except 7-9 years \& 10-12years age group, which were $9.1 \mathrm{mg} \& 10.5 \mathrm{mg}$ lower than the RDA. Vit A, thiamine, VitC intake were lower than the RDA. In case of riboflavin \& niacin in two age group 1-3 years \& 4-6years were higher than the RDA but in age group 7-9y \& 10-12y it was lower than the RDA.

Relation between children's IQ level with nutrient intake about all nutrients were not associated with IQ level except protein, thiamine, niacin \& zinc, which were highly significant with IQ level of the autistic children ( $\mathrm{p}$ value was 0.00$)$ where CI was $95 \%$ \& $(\mathrm{P}<0.05)$ (Table 5).

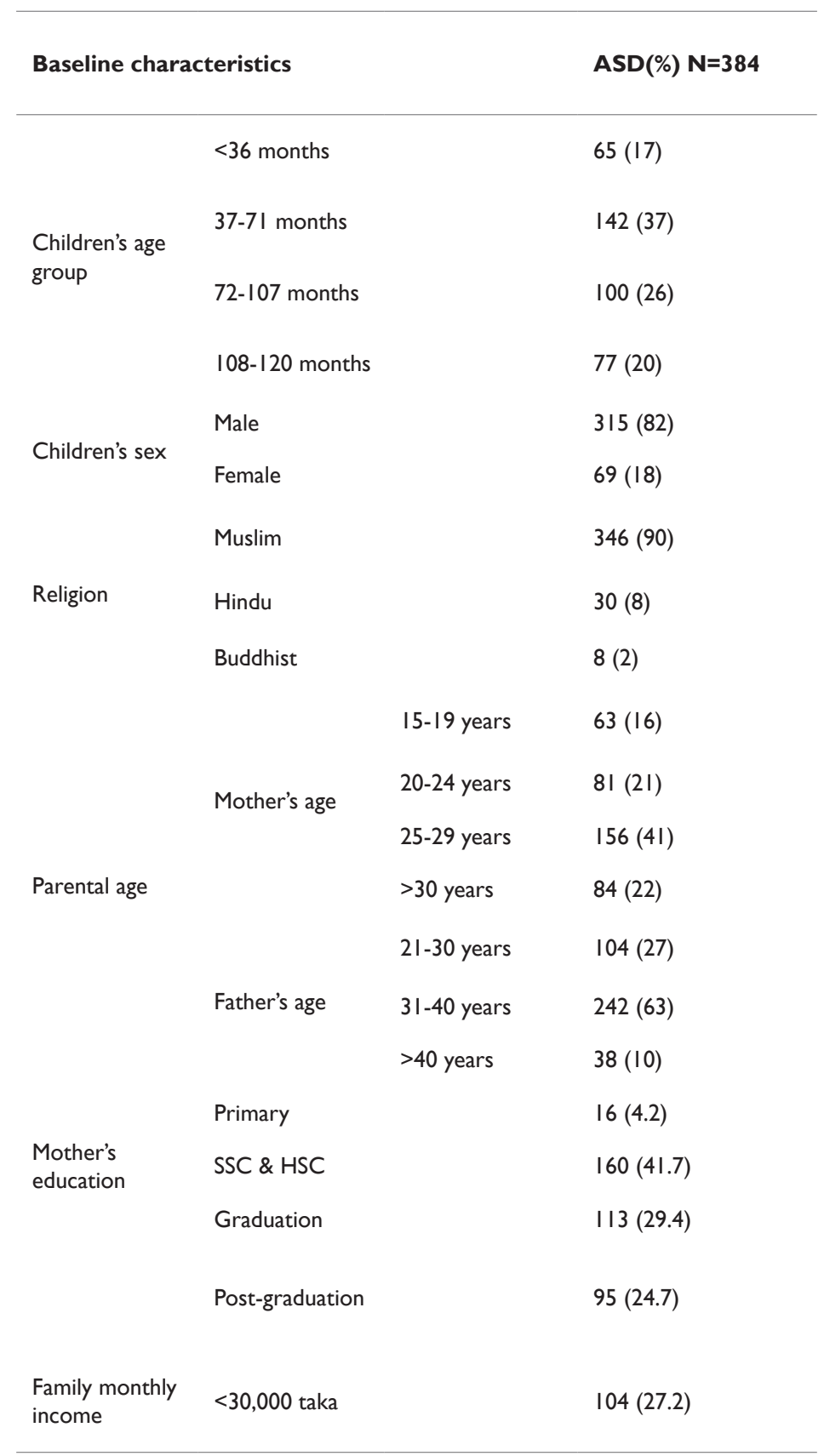


Table 2 IQ level of the study subjects $(n=384)$

\begin{tabular}{lll}
\hline IQ level & Frequency & Percentage \\
\hline$<69$ (significantly delayed performance) & 243 & $63.30 \%$ \\
$70-85$ (moderately delayed performance) & 94 & $24.50 \%$ \\
$85-$ II 4 (mildly delayed performance) & 4 & $12.20 \%$ \\
Psychological test & Frequency & Percentage \\
BSAID (age I-3.5yrs \& no speech, no performance) & 364 & 94 \\
WISC-R (6-I5yrs, with speech \& performance) & 10 & 3 \\
IBAS (2-9 yrs, no speech \& no performance) & 10 & 3 \\
\hline
\end{tabular}

Table 3 Distribution of ASD children by Per capita food consumption (by age) $(n=384)$

\begin{tabular}{|c|c|c|c|c|c|c|c|c|c|c|}
\hline Food items & $\begin{array}{l}\text { I-3y } \\
\text { Mean } \\
\text { (gm) }\end{array}$ & SD & $\begin{array}{l}\text { 4-6y } \\
\text { Mean } \\
\text { (gm) }\end{array}$ & SD & $\begin{array}{l}\text { 7-9y } \\
\text { Mean } \\
\text { (gm) }\end{array}$ & SD & $\begin{array}{l}\mid 0-12 y \\
\text { Mean } \\
(\mathrm{gm})\end{array}$ & SD & $\begin{array}{l}\text { Mean } \\
(\mathrm{gm})\end{array}$ & SD \\
\hline Cereal & 189 & 165 & 155 & 75 & 168 & 59 & 179 & 61 & 169 & 94 \\
\hline Rice & 132 & 169 & 102 & 74 & 120 & 61 & $|3|$ & 63 & 118 & 95 \\
\hline White potato & 5 & 18 & 9 & 27 & 12 & 23 & 13 & 25 & 10 & 24 \\
\hline Pulse \& nut & 3 & 4 & 7 & 24 & 8 & 16 & 10 & 21 & 7 & 19 \\
\hline Vegetable & 8 & 37 & 18 & 41 & 22 & 41 & 19 & 49 & 17 & 42 \\
\hline Fruits & 20 & 40 & 21 & 34 & 22 & 32 & 18 & 25 & 21 & 33 \\
\hline Poultry & 12 & 35 & 25 & 47 & 42 & 63 & 64 & 94 & 34 & 63 \\
\hline Eggs & 21 & 32 & 18 & 21 & 17 & 33 & 14 & 19 & 18 & 27 \\
\hline Fish & 37 & 41 & 58 & 71 & 53 & 46 & 44 & 36 & 50 & 55 \\
\hline Milk product & 130 & 140 & 133 & 152 & 75 & 115 & 40 & 73 & 99 & 134 \\
\hline Total food & 436 & 166 & 461 & 176 & 436 & 166 & 413 & $|5|$ & 441 & 168 \\
\hline
\end{tabular}

Table 4 Comparison of Nutrients intake and age group with RDA

\begin{tabular}{|c|c|c|c|c|c|c|c|c|c|c|c|c|}
\hline \multirow{2}{*}{ Nutrients } & \multicolumn{2}{|c|}{$|-3 y, 7|$} & \multicolumn{3}{|c|}{$4-6 y, 138$} & \multicolumn{3}{|c|}{$7-9 y, 109$} & \multicolumn{3}{|c|}{$10-12 y, 65$} & \multirow[b]{2}{*}{$\%$} \\
\hline & $M$ & RDA & $\%$ & $M$ & RDA & $\%$ & $\mathbf{M}$ & RDA & $\%$ & $M$ & RDA & \\
\hline Energy(kcal) & 852.8 & 754 & ++ & 804.8 & 1094 & $74 \%$ & 845.6 & 1375 & $61 \%$ & 871.3 & |59| & $55 \%$ \\
\hline Protein (g) & 38.3 & 19.9 & ++ & 44.5 & 31.0 & ++ & 46.1 & 37.1 & ++ & 48.0 & 44.4 & ++ \\
\hline Fat(gm) & 6.8 & 2.5 & ++ & 7.2 & 6.5 & ++ & 7.4 & 7.8 & + & 6.8 & 9.0 & $76 \%$ \\
\hline $\mathrm{Ca}(\mathrm{mg})$ & 419.2 & 240 & ++ & 592.4 & 226 & ++ & 492.7 & 269 & ++ & 364.6 & 301 & ++ \\
\hline iron (mg) & 9.3 & 4.6 & ++ & 9.4 & 8.3 & + & 9.1 & 10.3 & $88 \%$ & 10.5 & II.5 & $91 \%$ \\
\hline Vit.A (IU) & 619.2 & 1245 & $50 \%$ & 423.5 & 1099 & $39 \%$ & 540.2 & 1360 & $40 \%$ & 1050 & 1877 & $56 \%$ \\
\hline Thia (mg) & 0.3 & .38 & $79 \%$ & 0.4 & 0.65 & $62 \%$ & 0.5 & 0.87 & $57 \%$ & 0.5 & 1.04 & $48 \%$ \\
\hline Ribo (mg) & 0.3 & .23 & ++ & 0.3 & .31 & $97 \%$ & 0.3 & 0.49 & $61 \%$ & 0.3 & 0.44 & $68 \%$ \\
\hline Niacine (mg) & 6.1 & 4.8 & + & 7.1 & 10.0 & $71 \%$ & 8.9 & 13.5 & $66 \%$ & 10.8 & 16.0 & $68 \%$ \\
\hline Vit.C (mg) & 12.4 & 17.9 & $69 \%$ & 15.7 & 25.3 & $62 \%$ & 15.3 & 27.6 & $55 \%$ & 13.8 & 33.5 & $41 \%$ \\
\hline
\end{tabular}


Table 5 Association between nutrients and IQ level of autistic children $(n=384)$

\begin{tabular}{|c|c|c|c|c|c|}
\hline \multirow[t]{2}{*}{ Nutrients name } & \multicolumn{4}{|c|}{ IQ level } & \multirow{2}{*}{$\begin{array}{l}\text { (ANOVA table) } \\
\text { significance } \\
P<0.05\end{array}$} \\
\hline & Mean & SD & Mean & SD & \\
\hline Energy (kcal) & 816.1 & 365.2 & 263.8 & 836.9 & 0.11 \\
\hline Protein (g) & 41.9 & 20.9 & 24.9 & 44.4 & 0.00 \\
\hline Fat (g) & 6.99 & 5.03 & 5.23 & 7.13 & 0.46 \\
\hline $\mathrm{CH}(\mathrm{g})$ & 146.7 & 81.4 & 49.3 & 148.8 & 0.46 \\
\hline $\mathrm{Ca}(\mathrm{mg})$ & 505.2 & 377.2 & 545.9 & 492.8 & 0.48 \\
\hline Iron (mg) & 9.77 & 11.39 & 8.10 & 9.47 & 0.46 \\
\hline Vit A (IU) & 511.8 & 1338.3 & 2042.9 & 600.2 & 0.16 \\
\hline $\begin{array}{l}\text { Carotein } \\
(\cup \mathrm{gm})\end{array}$ & 1769.0 & 5058.4 & 3725.3 & 1727.0 & 0.82 \\
\hline Thia (mg) & .41 & .21 & .19 & .45 & 0.00 \\
\hline Ribo (mg) & .27 & .20 & .22 & .28 & 0.11 \\
\hline Niacine (mg) & 7.21 & 4.58 & 4.73 & 8.04 & 0.00 \\
\hline VitC (mg) & 14.28 & 13.62 & 16.32 & 14.76 & 0.40 \\
\hline Zinc (gm) & 312.4 & 157.0 & 155.7 & 339.2 & 0.00 \\
\hline
\end{tabular}

\section{Discussion}

Children with autism spectrum disorder (ASD) have so many problems. Of them atypical food intake and problems of food selectivity take them at risks of nutritional deficiencies. In one of case-control study, it would be found that comparison between ASD \& normal children's anthropometric measurement and food intake, the body mass indices were below of ASD than normal children. In case of food intake it was also observed that there was limited food variety and inadequacy of some intakes which ultimately made them malnourished. ${ }^{9}$ Our results showed that age group 1-3y, 4-6y,7$9 \mathrm{y}, 10-12 \mathrm{y}$ had consumed cereal 189gm, 155gm, 168gm \& 179gm respectively. Age group 1-3y, 4-6y,7-9y,10-12y had consumed rice $132 \mathrm{gm}, 102 \mathrm{gm}, 120 \mathrm{gm} \& 131 \mathrm{gm}$ respectively. Age group 1-3y, $4-6 \mathrm{y}, 7-9 \mathrm{y}, 10-12 \mathrm{y}$ had consumed potatoes $5 \mathrm{gm}, 09 \mathrm{gm}, 12 \mathrm{gm} \& 13$ gm respectively. Age group 1-3y, 4-6y,7-9y,10-12y had consumed pulse \& nut $3 \mathrm{gm}, 7 \mathrm{gm}, 8 \mathrm{gm} \& 10 \mathrm{gm}$ respectively. Age group 1-3y, 4-6y, 7-9y had consumed vegetables $8 \mathrm{gm}, 18 \mathrm{gm}, 22 \mathrm{gm} \&$ age group $7-9 \mathrm{y}$ had 19gm consumption. Age group 1-3y, 4-6y,7-9y,10-12y had consumed fruits $20 \mathrm{gm}, 21 \mathrm{gm}, 22 \mathrm{gm} \& 18 \mathrm{gm}$ respectively. Age group 1-3y, 4-6y,7-9y, 10-12y had consumed poultry $12 \mathrm{gm}, 25 \mathrm{gm}$, $42 \mathrm{gm} \& 64 \mathrm{gm}$ respectively. Age group 1-3y, 4-6y,7-9y,10-12y had consumed fish $37 \mathrm{gm}, 58 \mathrm{gm}, 53 \mathrm{gm} \& 44 \mathrm{gm}$ respectively. Age group $1-3 y, 4-6 y, 7-9 y, 10-12 y$ had consumed milk \& milk products $130 \mathrm{gm}$, $133 \mathrm{gm}, 75 \mathrm{gm} \& 40 \mathrm{gm}$ respectively. Relation between children's IQ level with nutrient intake about all nutrients were not associated with IQ level except protein, thiamine, niacin \& zinc, which were highly significant with IQ level of the autistic children ( $p$ value was 0.00 ). Based on the 2002 National Survey of Resident Nutritional Status in China, the rates of inadequacy intake and the borderline inadequacy intake were $9 \cdot 1$ and $41 \cdot 8 \%$ for vitamin A, respectively; the dietary $\mathrm{Ca}$ intake was $238 \mathrm{mg} / \mathrm{d}$, which is only one-third of the adequate intakes in Chinese children below 6 years of age. ${ }^{10}$ Several studies have also found that children with autism consume significantly lower amounts of $\mathrm{Ca}$ than those without autism. ${ }^{11-13}$ Based on the detected serum biochemical assessment, serum vitamin A and Ca levels in children with autism were significantly lower compared with those in children without autism (the serum Ca level of children with autism was also less than the reference range). A previous study reported that no significant difference is observed in the serum Ca levels between children with and without autism, and the detected values are within the normal reference range. ${ }^{14}$ However, the serum Ca level is increased when the $\mathrm{Ca}$ deposited in the skeleton is mobilized, thereby resolving $\mathrm{Ca}$ inadequacy. The proportion of $\mathrm{Zn}$ intake inadequacy in Chinese children is approximately $50 \% .{ }^{15} \mathrm{Zn}$ deficiencies may be related with the characteristics of the Chinese diet, in which cereals constitute the main staple food. So for this case inadequacy of fruits, the mean vitamin $\mathrm{C}$ intake level in that region, children with autism was inadequate \& significantly lower than that of the typically developing children. No differences were observed in vitamin B12 levels between children with and without autism in our study. However, the serum folate levels in children with autism significantly decreased. A recent study has reported that serum homocysteine levels significantly increase and folate and vitamin $\mathrm{B}_{12}$ levels significantly decrease in children with autism compared with those in typically developing controls. ${ }^{16}$ Some studies have also demonstrated that children with autism exhibit impaired methylation and homocysteine metabolism. ${ }^{17,18}$ Folate and vitamin B12 have an important function in homocysteine metabolism. Therefore, the folate defect observed in our study may lead to homocysteine accumulation in the body of children with autism. Sometimes it would be suggested that children with autism spectrum disorder were at a higher risk for underweight, eating more legumes, vegetables, fiber, and some micronutrients (traditional Mediterranean diet) but fewer dairy and cereal products, and less iodine, sodium, and calcium than their typically developing peers. It would be also observed differences existed in total energy intake but healthy eating index and food variety score differences were not significant. Sometimes Autism spectrum disorder group had no dietary recommendations for thiamin, riboflavin, vitamin $\mathrm{C}$, or calcium. Risk of inadequate intake of fiber, vitamin E, and sodium was lower in children with autism spectrum disorder than typically developing children. From the research it would be concluded that 
(1) risk of inadequate intake of some micronutrients in children with autism spectrum disorder and (2) cultural patterns and environment may influence food intake and anthropometric characteristics in autism spectrum disorder. ${ }^{9}$ There is growing interest in possible dietary involvement in the etiology and treatment of Autistic Spectrum Disorders (ASD). Research has focused on the physiological and behavioral effects of dietary change but has not examined the effect of exclusion diets on nutritional intake. Nutrient intakes fell below the Lower Reference Nutrient Intake (LRNI) in 12 children (32\%) for zinc, calcium, iron, vitamin $A$, vitamin $B_{12}$ and riboflavin in the no diet group and four children (50\%) for zinc and calcium in the diet group. Fruit and vegetable intakes were higher and cereal, bread and potato consumption were lower in those children using gluten and/ or casein free diets. No significant differences in the energy, protein and micronutrient intakes were found between the two groups of children. ${ }^{19}$ Intelligence is a touchy, and complicated, subject when it comes to autism. Dr. Leo Kanner first described the condition named autism 70 years ago and noted that some children were thought to be intellectually disabled. At that time their social, communication and behavior problems lead them the appearance of intellectual disability to a new world which was unaware of autism's existence. American psychiatrists updated their diagnostic manual in 2013; they faced a lot of difficulty with IQ tests and autism. Although the manual says intellectual disability is common in autism, it also difficult that measuring a child's intellectual ability may be complicated by the symptoms of autism. This study got $63 \%$ autistic children had IQ level $<69$ (known as significantly delayed performance by standard method), 24\% had IQ level 70-85 (known as moderately delayed performance) \& nearly $12 \%$ of the children had IQ level $85-114$ (known as mildly delayed performance). From 1966 to 1998, studies found that about only one-fifth of the people with ASD functioned in the "normal range" of intelligence, according to a 1999 review.161 But years later, in 2014, a U.S. In that study it would be found almost half of the children with ASD had average or above average intelligence, an IQ score above 85 . Less than a third of the children with autism had intellectual disability, and $23 \%$ had IQ scores in the "borderline range" from 71 to $85 . .^{20}$ Effective interventions have lessened the severity of children's language and intellectual delays, experts say. ${ }^{21}$

\section{Conclusion of the study}

In this study various aspect of nutritional deficiencies were observed in autistic children in our country. They were exhibited several abnormal eating behaviour. Energy intake was found lower than the RDA. Mean intake of protein \& calcium were higher than the RDA in all age group but fat intake was lower in only 10-12y age group. Mean intake of iron were higher than the RDA in all the age group except 7-9 years \& 10-12years age group. VitA, thiamine, VitC intake were lower than the RDA in all age grouped. Riboflavin \& niacin were higher in two age group 1-3y \& 4-6y but those were lower than the RDA in age group 7-9y \& 10-12y. Low intake of protein, thiamine, niacin \& zinc were related with the low IQ level in autistic child. However all nutrient intake was not related with IQ level.

\section{Recommendations}

In order to address the problem of ASD education level of the parents about autism must be increased. ASD problem symptoms \& management of Autism Spectrum Disorders should be included in the curriculum of different education level in Bangladesh. The ASD children should be provided with adequate \& balanced diet to improve their Nutrient intake \& IQ level as it was found that some of the children didn't get adequate calories and micronutrients. Awareness raising programme should be arranged for the mass population. Electronic $\&$ print media can play an important role in this regard as well as community clinics. Study throughout the country will be helpful to explore the overall situation of the ASD children.

\section{Acknowledgements}

None.

\section{Conflict of interest}

The authors declare no conflict of interest.

\section{References}

1. Levy SE, MandellDS, SchultzRT.Autism. Lancet.2009;374(9701):16271638.

2. World Health Organization. Pervasive developmental disorders. 2007.

3. Rogers SJ. What are infant siblings teaching us about autism in infancy? Autism Res. 2009;2(3):125-137.

4. Rapin I, Tuchman RF. Autism: definition, neurobiology, screening, diagnosis. PediatrClin North Am. 2008;55(5):1129-1146.

5. Filipek PA, Accardo PJ, Baranek GT et al. The screening and diagnosis of autistic spectrum disorders. J Autism Dev Disord. 1999;29(6):439-484.

6. Legge B. Can't Eat, Won't Eat: Dietary Difficulties and Autistic Spectrum Disorders. London: Jessica Kingsley Publishers; 2002.

7. Tomchek SD, Dunn W. Sensory processing in children with and without autism: A comparative study using the Short Sensory Profile. Am J OccupTher. 2007;61:190-200.

8. Twachtman-Reilly J, Amaral SC, Zebrowski PP. Addressing feeding disorders in children on the autism spectrum in school-based settings: Physiological and behavioral issues. Lang Speech Hear Serv Sch. 2008;39:261-272.

9. Cornish E. Gluten and casein free diets in autism: a study of the effects on food choice and nutrition. J Hum Nutr Diet. 2002;15:261-269.

10. Cermak SA, Curtin C, Bandini LG. Food selectivity and sensory sensitivity in children with autism spectrum disorders. J Am Diet Assoc. 2010;110:238-246.

11. Zhao LY, Yu DM, Liu AD, et al. Analysis of health selective survey result of children and pregnant/lying-in women in China in 2006. J Hyg Res. 2008;37:5-67.

12. Shearer TR, Larson K, Neuschwander J, et al. Minerals in the hair and nutrient intake of autistic children. J Autism DevDisord. 1982;12:25-34.

13. Adams JB, Audhya T, McDonough-Means S, et al. Nutritional and metabolic status of children with autism vs. neurotypical children, and the association with autism severity. NutrMetab. 2011;8:34-66.

14. Ma G, Li Y, Jin Y, et al. Assessment of intake inadequacy and food sources of zinc of people in China. Public Health Nutr. 2007;10:848-554.

15. Ali A, Waly MI, Al-Farsi YM, et al. Hyperhomocysteinemia among Omani autistic children: a case-control study. ActaBiochim Pol. 2011;58:547-551.

16. James SJ, Cutler P, Melnyk S, et al. Metabolic biomarkers of increased oxidative stress and impaired methylation capacity in children with autism. Am J ClinNutr. 2004;80:1611-1617.

17. James SJ, Melnyk S, Fuchs G, et al. Efficacy of methylcobalamin and folinic acid treatment on glutathione redox status in children with autism. Am J ClinNutr. 2009;89:425-430. 
18. Fombonne E. The epidemiology of autism: a review. Psychological Medicine. 1999;29(4):769-786.

19. Yin SA, Lai JQ. Nutrition and Health State of 0-6 Years Chinese Children, The Survey of Nutrition and Health State of Chinese Residents in 2002. Beijing: People's Medical Publishing House; 2008.
20. CDC. Prevalence of Autism Spectrum Disorder Among Children Aged 8 Years - Autism and Developmental Disabilities Monitoring Network, 11 Sites, United States, 2010. 2014.

21. Rogers SJ, Vismara L. Interventions for Infants and Toddlers at Risk for Autism Spectrum Disorder. 4thed. Volkmar FR, editor. Hoboken, NJ: John Wiley \& Sons; 2014:739-769. 